\title{
Analysis of Internal Force of the Cable-stayed Aqueduct Structure
}

\author{
ZHANG Zhendong, CHEN Ling, ZHOU Run, YE Yong*, Chen Xuejian, Liu Donglin \\ College of Hydraulic \& Environmental Engineering, Three Gorges University, Yichang, Hubei, China
}

E-mail address: yyeeong@aliyun.com

*Corresponding author (Faculty Adviser)

\begin{abstract}
Aqueduct is a kind of cross bridge building which can cross the channel, depressions, roads and railways .In the paper, based on the aqueduct design, aqueduct model making, aqueduct structure calculation and static load experiment, the aqueduct model is made to solve the problem of analysis of the internal force of the cable-stayed aqueduct structure and obtained the changing value of model deformation with the increase of load. Experiment results show that the boundary load of elastic deformation and plastic deformation of model is $30 \mathrm{~kg}$, and the ultimate load is $60 \mathrm{~kg}$.Using structural solver to model and check the most likely failure point of aqueduct with $52 \mathrm{~kg}$ load, and shows that It can meet the design requirements, and verify the feasibility of the model design.
\end{abstract}

Keywords-cable-stayed aqueduct; load bearing; Internal force; elastic deformation; plastic deformation

\section{MODEL DESIGN}

\section{A. Cross section design}

There are four main forms of the aqueduct section, rectangular, trapezoid, $\mathrm{U}$ type, semicircle. The model is made by ABS square plastic pipe, which is not easy to bend, so the circular cross section and U type are abandoned, and Rectangular cross section is chosen by considering the complexity of calculation and model-making, low requirements of material. The rectangular cross section, based on the hydraulic optimum section size breadth depth ratio of 2:1[1], the groove depth $\mathrm{h}$ is designed to be $120 \mathrm{~mm}$ and the width b is $200 \mathrm{~mm}$, the length of groove $\mathrm{L}$ is $1000 \mathrm{~mm}$.

\section{B. Design of support form}

The aqueduct can be divided into arch, truss type, combined type and suspension or cable stayed

type[2] according to the supporting structure .From the structural point of view, the cable-stayed type structure is a statically indeterminate structure, whose structural stability is good[3], and the cable stayed aqueduct are used more and more widely in practice, so the cable stayed structure aqueduct are chosen to study.

Cable design: considering the appearance of model, the model consists of 40 cables. There are 10 cables at each of end, and the distance between each cable is $38 \mathrm{~mm}$.

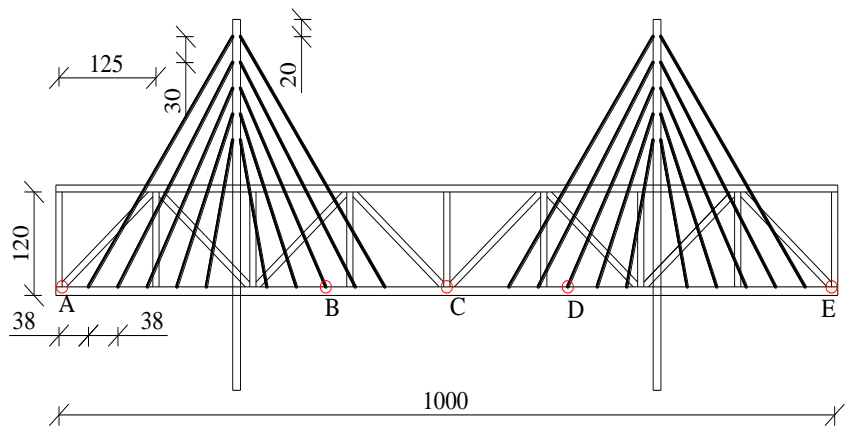

Figure 1. Elevation view of cable-stayed aqueduct model

The design of the supporting rod: overhanging beam is chosen and the support is moved to the center of span with 0.207 times of the span to reduce the rod end bending moment, .At the same time, taking into account aesthetic and symmetry of the whole structure, the distance between the main support rod and the rod end is designed to be $228 \mathrm{~mm}$.

The final design of the cable-stayed aqueduct is shown in Fig .1.

\section{Model MaKing}

ABS square plastic tube adopts two forms of cross section with outside diameter $8 * 8(\mathrm{~mm})$ and $10 * 10(\mathrm{~mm})$.The model of the production process is divided into three stages of preparation production, maintenance[4].

In the early stages of preparation, the materials and related tools need to be ready, and then the bearing rod will be cut according to the design. In the medium-term production stage, the model will be 
completed after the square tube being bonded with $\mathrm{AB}$ glue and the cable being fixed, the white cardboard being paved. Maintenance is to make sure that the aqueduct looks properly and check them at regular time.

\section{MODEL TEXT}

\section{A. Water load experiment}

Water load text[5] is done after the completion of aqueduct, and in order to prevent the water soak the white cardboard and reduced model bearing capability, a layer of waterproof membrane is paved on it. During the experiment[6], the load is added by step way, and set five control point of displacement, A,B,C,D,E, like the Fig .1, and record the data of displacement when adding load.

Add water slowly at both ends of the model, and measure the distance between the displacement control point and the reference plane after the water is stabled in the model.

The aqueduct has been filled with water and can no longer continue adding load when the total mass of water is added to $24 \mathrm{~kg}$. The deformation value of the midpoint in the main girder of aqueduct under the load is recorded in table 1 .

TABLE I. RECORD TABLE OF DISPLACEMENT OF MIDPOINT UNDER WATER LOAD

\begin{tabular}{|c|c|c|c|c|c|}
\hline The quality of the water $(\mathrm{kg})$ & 8 & 10 & 15 & 20 & 24 \\
\hline The displacement of the center $(\mathrm{mm})$ & 1 & 1.7 & 2.5 & 3 & 4.1 \\
\hline
\end{tabular}

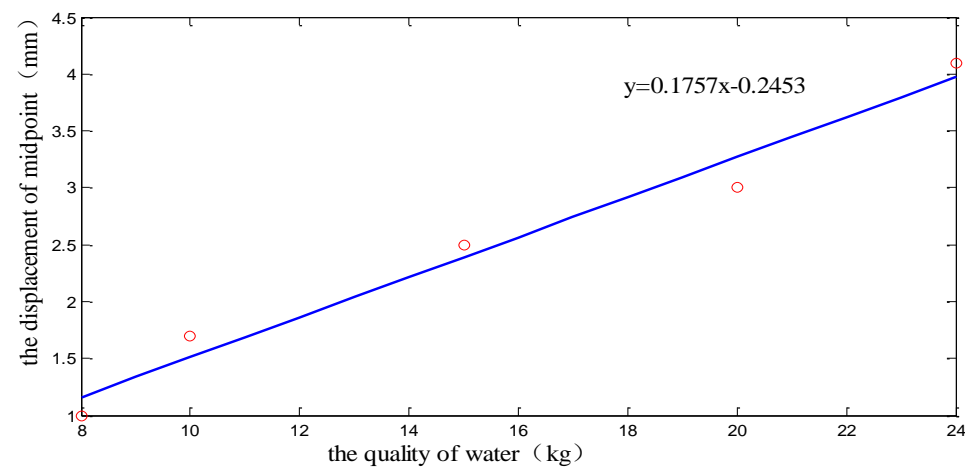

Figure 2. Fitting chart of center displacement changes with the load

The displacement of midpoint is measured to be zero after all the load be removed. Deformation of the model in water load experiment is supposed to be elastic deformation. And the matlab[7] software is used to draw the scatter diagram of the experimental data to verify the hypothesis, as shown in Fig .2. And through regression analysis, the trend line of the displacement value of midpoint with the changing load is obtained, the equation is $y=0.1575 x-0.2453$, and the regression coefficient $R^{2}=0.9716$, which fits well.

Based on the analysis above, the relationship between displacement and water load of model in the experiment is proved to be linear relation, and the hypothesis is also confirmed.

\section{B. Sand load experiment}

Iron sand with a greater density is used to carry on the load experiment to test the model carrying capacity further more. Repeat the operation of water load experiment, and displacement value of main girder of the aqueduct with greater loads is recorded in table 2 .

TABLE II. RECORD TABLE OF DISPLACEMENT OF MIDPOINT UNDER IRON SAND LOAD

\begin{tabular}{|c|c|c|c|c|c|}
\hline The quality of iron sand $(\mathrm{kg})$ & 30 & 35 & 40 & 45 & 52 \\
\hline The displacement of the center $(\mathrm{mm})$ & 5 & 5.5 & 6.2 & 6.9 & 10 \\
\hline
\end{tabular}

It's obvious that there are some deformations which can not be restored in the model after the load be removed, so the deformation of the model in iron sand load experiment is supposed to be plastic deformation, and the matlab software is also used to draw the scatter diagram of the experimental data to verify the hypothesis, as shown in Fig .3. And through regression analysis, linear and quadratic equation are chosen to fit the data, and quadratic relation is found to fit better by comparison, its regression coefficient is 0.9853 . 

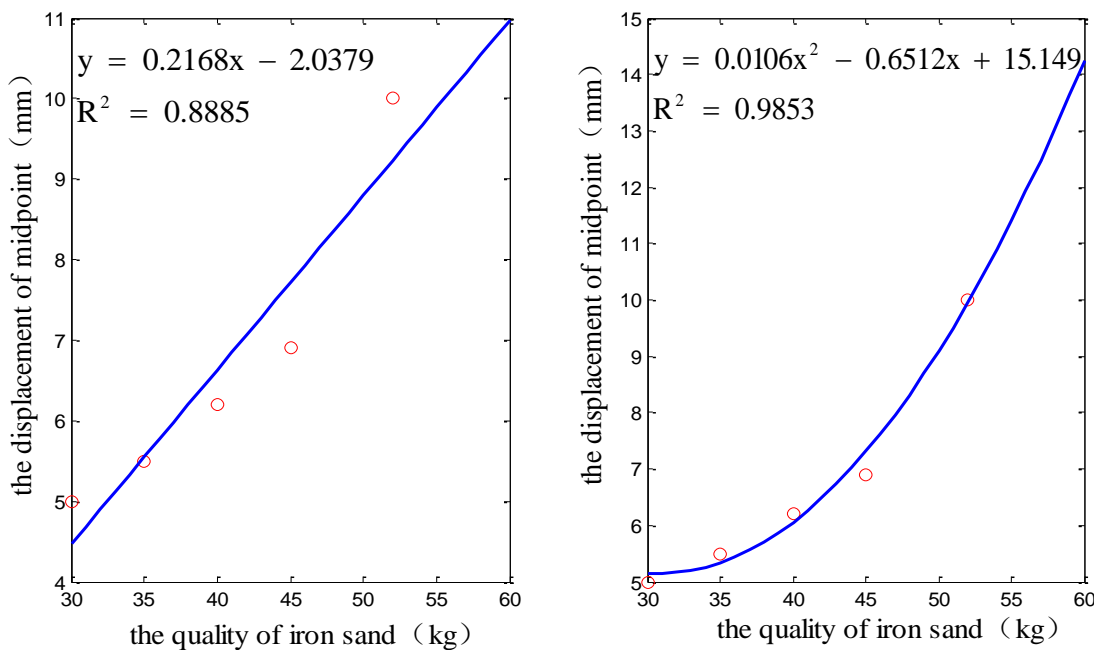

Figure 3. Fitting chart of linear and quadratic relation of displacement changes with load

Based on the analysis above, it can be seen that the deformation of model is plastic deformation when the load on it is more than $30 \mathrm{~kg}$, and $30 \mathrm{~kg}$ can be the demarcation load of elastic deformation and plastic deformation of the model.

\section{MOdEl CALCULATION}

\section{A. Displacement calculation}

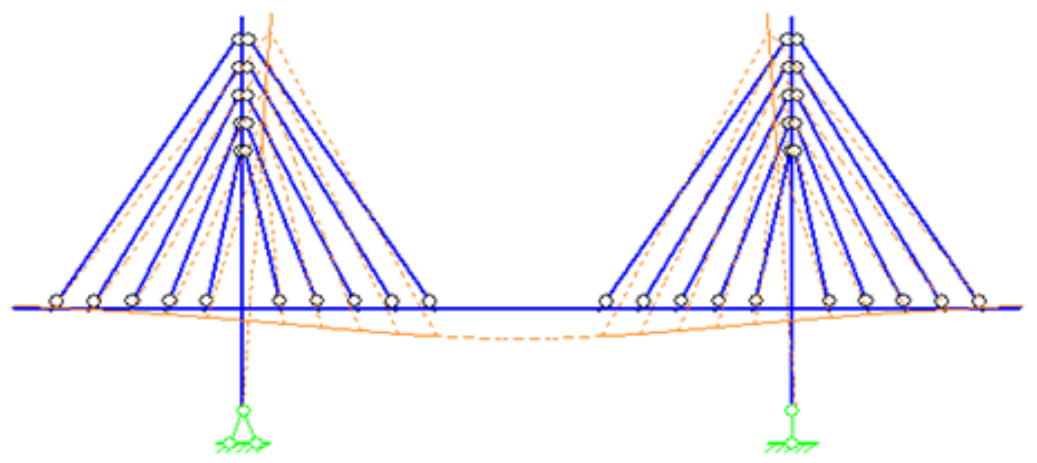

Figure 4. Displacement characteristic chart with structural solver

Based on the analysis of the picture above, the displacement characteristics of the structure are as follows:

(1) The deformation of model is axial symmetry.

(2) The deformation of middle of the main girder
1) Comparison of displacement characteristic

As shown in Fig .4, the three-dimensional cable-stayed aqueduct model is simplified as two-dimensional graphics, and the structural solver is used to modeling and draw the displacement diagram of the whole structure under the maximum load.

TABLE III. RECORD TABLE OF DISPLACEMENT VALUE OF CONTROL POINT

\begin{tabular}{|c|c|c|c|c|c|}
\hline Displacement point & A & B & C & D & E \\
\hline The value of displacement $(\mathrm{mm})$ & 1.5 & -7.2 & -10 & -7 & 1.3 \\
\hline
\end{tabular}

Based on the analysis of table 3 , the characteristic of the main girder with the load of $52 \mathrm{~kg}$ is consistent with the conclusions above.

2) Error analysis of displacement

The displacement value of center point of the main girder is measured every $5 \mathrm{~kg}$ from $30 \mathrm{~kg}$ to $50 \mathrm{~kg}$ in the is bigger than that of both ends, and the displacement of the middle is downward, but the two ends is on the opposite.

The displacement value of five control point under the load of $52 \mathrm{~kg}$ is shown in table 3 . iron sand load experiment. All weight is spread average on the main girder and obtains the value of uniform load when structural solver is used to modeling. And error analysis is made by comparing the calculated results of the structural solver and experiment data, the specific results are shown in table 4 . 
TABLE IV. STRUCTURE CALCULATION AND EXPERIMENTAL DISPLACEMENT VALUE COMPARISON TABLE

\begin{tabular}{|c|c|c|c|c|}
\hline $\begin{array}{c}\text { The quality of } \\
\text { iron sand } \\
(\mathrm{kg})\end{array}$ & $\begin{array}{c}\text { Uniform load } \\
(\mathrm{N} / \mathrm{m})\end{array}$ & $\begin{array}{c}\text { The displacement value of } \\
\text { center point of the main girder of } \\
\text { structural solver }(\mathrm{mm})\end{array}$ & $\begin{array}{c}\text { The displacement } \\
\text { value of center point } \\
\text { of the main girder of } \\
\text { experiment }(\mathrm{mm})\end{array}$ & $\begin{array}{c}\text { Error } \\
\text { analysis }\end{array}$ \\
\hline 30 & 147 & 4.2552 & 5 & $17.50 \%$ \\
\hline 35 & 171.5 & 4.9673 & 5.5 & $10.72 \%$ \\
\hline 40 & 196 & 5.6735 & 6.2 & $9.28 \%$ \\
\hline 45 & 220.5 & 6.3827 & 10 & $8.10 \%$ \\
\hline 52 & 254.8 & 7.3246 & $36.53 \%$ \\
\hline
\end{tabular}

The three-dimensional problems are simplified as a two-dimensional problem by Structural solver, there are some errors between the calculation results and experimental results, but the errors are in the allowable range.

\section{B. Stress calculation}

1) Mechanical analysis of rod

The cable can be treated as rigid body when it tensions considering the principle of rigidization. The cable is made of Cylindrical nylon rope, whose diameter is $1.4 \mathrm{~mm}$, and the maximum axial force of cable is 19.67 N.The maximum stress[8][9] is

$$
\sigma_{t}=\frac{F}{A}=\frac{19.67}{\frac{\pi}{4} \times\left(1.4 \times 10^{-3}\right)^{2}}=12.8 \mathrm{MPa}<70 \mathrm{MPa}
$$

(Meets the strength conditions )

The supporting rod is made of square plastic pipe, whose length is $10 \mathrm{~mm}$, and the maximum axial force of the rod is $127.4 \mathrm{~N}$. The maximum stress is

$$
\sigma_{c}=\frac{F}{A}=1.27 \mathrm{MPa}<30 \mathrm{MPa}
$$

(Meets the strength conditions )

\section{2) Mechanics analysis of beam}

The girder is made of square plastic pipe, whose length is $10 \mathrm{~mm}$, and the girder is main part to bear the bending moment, and the maximum bending moment is 2.8N.m. The maximum stress is compressive stress, which occurs at the lower edge, it's

$$
\sigma_{t}=\frac{M}{W}=\frac{2.8}{\frac{10^{-2} \times\left(10^{-2}\right)^{2}}{6}}=16.8 \mathrm{MPa}<30 \mathrm{MPa}
$$

(Meets the strength conditions )

The intersection of main beam and the supporting rod bears both axial force and bending moment, the bending moment is $0.38 \mathrm{~N} . \mathrm{m}$, the axial force is $25.7 \mathrm{~N}$, the maximum compressive stress is

$\sigma_{c}=\frac{F}{A}+\frac{M}{W}=2.54 M P a<30 M P a$

(Meets the strength conditions )

\section{SUMMARY}

(1) The errors of aqueduct model experimental data and the calculated value of structural solver are in the allowable range, which shows that the model making and relative calculation is accurate[10].

(2)Through theoretical calculation and actual loading experiment of aqueduct, the limit load of model is about $60 \mathrm{~kg}$, and the failure point is at the lower edge of the midpoint of the main girder, and the displacement value is $10 \mathrm{~mm}$.

(3)The demarcation load of elastic deformation and plastic deformation of the model is $30 \mathrm{~kg}$.

\section{REFERENCES}

[1] C.G.Wu, Hydraulics, The fourth edition, Sichuan: Higher Education Press, 2007.

[2] J.Y.Lin, Hydraulic structures, The fifth edition, Beijing: China WaterPower Press, 2008.

[3] C.Z.Wu,Z.P.Zhang,H,M,Yan: Study on design of aqueduct of the midline of South-to-North Water Diversion[J].Yellow River,2003, 25( 3) ,P:42-43.

[4] D.S.Cao,P.Hua,H.Z.Zhu,X.Deng: The manufacture of the simulation experiment model of large prestressed concrete aqueduct[J].Journal of Wuhan University (Engineering Edition), 2004(05).

[5] S.B.Zhao,Z.Y.Hu,X.K.Li: Experimental study on the stress of large reinforced concrete aqueduct with multi longitudinal beams[J].Journal of Hydroelectric Engineering, 1999(03).

[6] Huizhu Zhu, 1Department of Irrigation and Drainage, Wuhan University of Hydraulic \& Electric Engineering, Irrigation and Drainage Systems, 1994, Vol.8 (2), pp.83-95, doi:10.1007/BF00881177

[7] Andy H.Register. A Guide to MATLAB Object-Oriented Programming. SciTech Publishing Inc.2007.

[8] Long Yuqiu, Chief Editor Bao Shihua. Structure Mechanics (M) Volume one. Second edition

[9] Cheng Yongdong, Cai Jianhua 0.2 kind of new aqueduct designs and the computation example. Beijing: Water conservation water and electricity publishing house, 1993

[10] Zhu Huizhu, Chen Deliang, manages maple tree year writing. Aqueduct. Chinese Water conservation Water and electricity Publishing house, 2009 